\title{
Lichen Nitidus
}

Alys S. Jordan, DO; Margaret C. Green, DO; Daryl J. Sulit, MD

From the Naval Medical Center San Diego in California (Drs Jordan, Green, and Sulit) and the Uniformed Services

University of the Health Sciences School of Medicine in San Diego (Dr Sulit)

Dr Jordan is a first-year resident, and Dr Green is a

dermatopathology fellow.

Disclaimer: The views expressed herein are those of

the authors and do not necessarily reflect the official

policy or position of the Department of the United States Navy, the Department

of Defense, or the US Government.

Financial Disclosures: None reported

Support: None reported.

Address correspondence to

Alys S. Jordan, DO, 34800 Bob Wilson Dr, San Diego, CA 92134-1098.

Email alys.s.jordan.mil@mail.mil Submitted February 3, 2019; revision received March 5, 2019; accepted March 15, 2019.

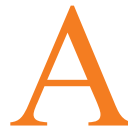
25-year-old man presented with a 5-year history of small asymptomatic bumps on his extremities and trunk. He denied any oral lesions or nail changes. Examination revealed multiple 1- to 2-mm monomorphic, hypopigmented, shiny papules symmetrically distributed on the neck, trunk, elbows, hands (image $\mathbf{A}$ and image B), popliteal fossae, dorsal feet, and ankles. A 4-mm punch biopsy found a "ball" of lichenoid and granulomatous inflammation with occasional giant cells in the papillary dermis, cupped laterally by "claw-like" extensions of acanthotic epidermal rete, consistent with lichen nitidus.

Lichen nitidus typically presents as multiple, flesh-colored, tiny, shiny papules found on flexor surfaces of the upper extremities, genitalia, and anterior trunk. ${ }^{1,2}$ Similar to lichen planus and psoriasis, lichen nitidus can develop in areas of trauma to the skin, which is known as the Koebner phenomenon. ${ }^{3}$ The diagnosis of lichen nitidus is usually clinical, but a punch biopsy of a

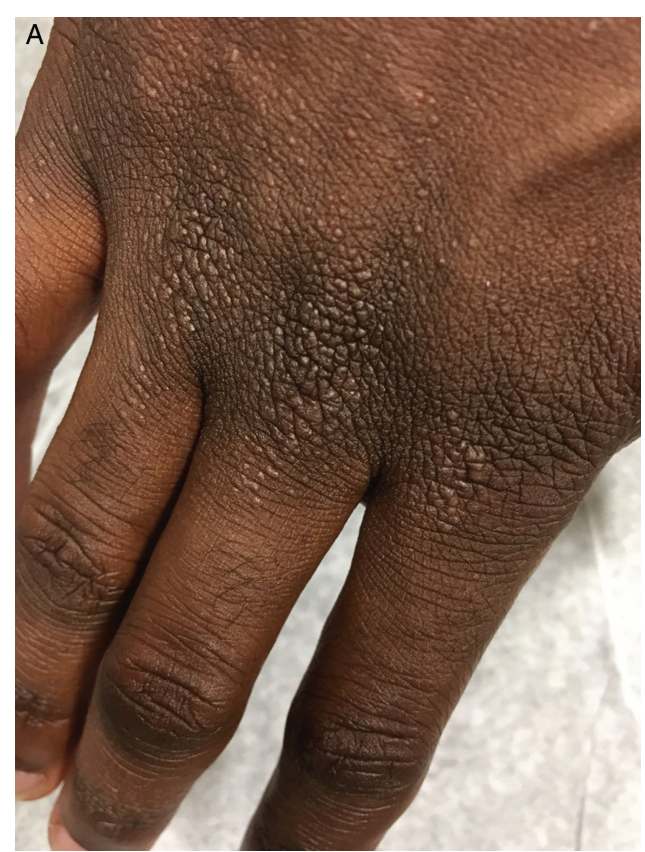

representative papule should be performed if the diagnosis is in question or if there is a lack of response to empiric treatments. Lichen nitidus typically self-resolves after a few months to a year. However, if the lesions persist or are symptomatic, treatment options are aimed at reducing associated inflammation. ${ }^{4,5}$ (doi:10.7556/jaoa.2019.119)

\section{References}

1. Lapins NA, Willoughby C, Helwig EB. Lichen nitidus. Cutis. 1978;21:634-637.

2. Synakiewicz J, Polanska A, Bowszyc-Dmochowska M, et al. Generalized lichen nitidus: a case report and review of the literature. Postepy Dermatol Alergol 2016;33(6):488-490 doi:10.5114/ada/2016.63890

3. Cho EB, Kim HY, Park EJ, Kown IH, Kim KH, Kim KJ . Three cases of lichen nitidus associated with various cutaneous diseases. Ann Dermatol. 2014;26(4):505-509.

4. Libow LF, Coots NV. Treatment of lichen planus and lichen nitidus with itraconazole: reports of six cases. Cutis. 1998;62 (5):247-248

5. Park JH, Choi YL, Kim WS, et al., Treatment of generalized lichen nitidus with narrowband ultraviolet B. J Am Acad Dermatol. 2006;54:545-546.

๑) 2019 American Osteopathic Association

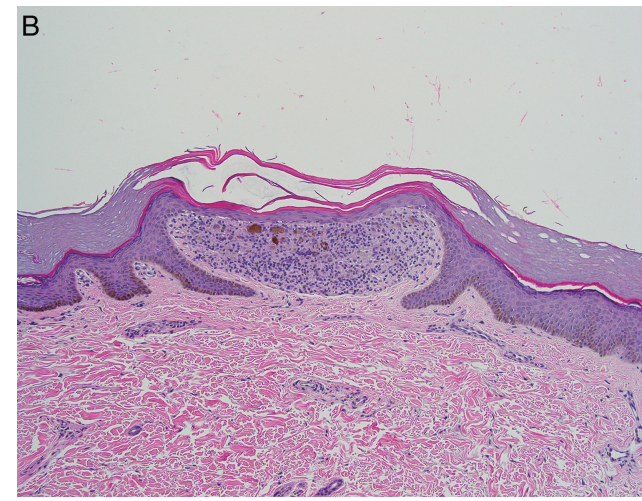

